\title{
The major histocompatibility complex (Mhc) class IIB region has greater genomic structural flexibility and diversity in the quail than the chicken
}

\author{
Kazuyoshi Hosomichi ${ }^{1}$, Takashi Shiina ${ }^{1}$, Shingo Suzuki ${ }^{2}$, Masayuki Tanaka ${ }^{2}$, \\ Sayoko Shimizu$^{1}$, Shigehisa Iwamoto ${ }^{2}$, Hiromi Hara ${ }^{2}$, Yutaka Yoshida ${ }^{2}$, \\ Jerzy K Kulski1,3, Hidetoshi Inoko* ${ }^{* 1}$ and Kei Hanzawa*†2
}

\begin{abstract}
Address: ${ }^{1}$ Department of Molecular Life Science, Division of Basic Medical Science and Molecular Medicine, Tokai University School of Medicine, 143 Shimokasuya, Isehara, Kanagawa 259-1143, Japan, ${ }^{2}$ Laboratory of Animal Physiology, Faculty of Agriculture, Tokyo University of Agriculture, 1737 Funako, Atsugi, Kanagawa 243-0034, Japan and ${ }^{3}$ Centre for Comparative Genomics, School of Information Technology, Murdoch University, Murdoch, WA 6150, Australia

Email: Kazuyoshi Hosomichi - hoso@is.icc.u-tokai.ac.jp; Takashi Shiina - tshiina@is.icc.u-tokai.ac.jp; Shingo Suzuki - 53050010@nodai.ac.jp; Masayuki Tanaka - matanaka@jbirc.aist.go.jp; Sayoko Shimizu - sshimizu@is.icc.u-tokai.ac.jp; Shigehisa Iwamoto - 54050001@nodai.ac.jp; Hiromi Hara - hiromi-h@nodai.ac.jp; Yutaka Yoshida - yoshida@nodai.ac.jp; Jerzy K Kulski - jkulski@ccg.murdoch.edu.au;

Hidetoshi Inoko* - hinoko@is.icc.u-tokai.ac.jp; Kei Hanzawa* - khanzawa@nodai.ac.jp

* Corresponding authors †Equal contributors
\end{abstract}

Published: 21 December 2006

BMC Genomics 2006, 7:322 doi:10.1186/1471-2164-7-322
Received: 02 October 2006

Accepted: 21 December 2006

This article is available from: http://www.biomedcentral.com/I47I-2/64/7/322

(C) 2006 Hosomichi et al; licensee BioMed Central Ltd.

This is an Open Access article distributed under the terms of the Creative Commons Attribution License (http://creativecommons.org/licenses/by/2.0), which permits unrestricted use, distribution, and reproduction in any medium, provided the original work is properly cited.

\begin{abstract}
Background: The quail and chicken major histocompatibility complex (Mhc) genomic regions have a similar overall organization but differ markedly in that the quail has an expanded number of duplicated class I, class IIB, natural killer (NK)-receptor-like, lectin-like and BG genes. Therefore, the elucidation of genetic factors that contribute to the greater Mhc diversity in the quail would help to establish it as a model experimental animal in the investigation of avian Mhc associated diseases.

Aims and approaches: The main aim here was to characterize the genetic and genomic features of the transcribed major quail MhcllB (CojallB) region that is located between the Tapasin and BRD2 genes, and to compare our findings to the available information for the chicken MhClIB (BLB). We used four approaches in the study of the quail MhcllB region, (I) haplotype analyses with polymorphic loci, (2) cloning and sequencing of the RT-PCR CojallB products from individuals with different haplotypes, (3) genomic sequencing of the CojallB region from the individuals with the different haplotypes, and (4) phylogenetic and duplication analysis to explain the variability of the region between the quail and the chicken.

Results: Our results show that the Tapasin-BRD2 segment of the quail Mhc is highly variable in length and in gene transcription intensity and content. Haplotypic sequences were found to vary in length between 4 to II kb. Tapasin-BRD2 segments contain one or two major transcribed CojallBs that were probably generated by segmental duplications involving c-type lectin-like genes and NK receptor-like genes, gene fusions between two CojallBs and transpositions between the major and minor CojallB segments. The relative evolutionary speed for generating the MhcllBs genomic structures from the ancestral BLB2 was estimated to be two times faster in the quail than in the chicken after their separation from a common ancestor. Four types of genomic rearrangement elements (GRE), composed of simple tandem repeats (STR), were identified in the MhcllB genomic segment located between the Tapasin-BRD2 genes. The GREs have many more STR numbers in the quail than in the chicken that displays strong linkage disequilibrium.
\end{abstract}


Conclusion: This study suggests that the Mhc classllB region has a flexible genomic structure generated by rearrangement elements and rapid SNP accumulation probably as a consequence of the quail adapting to environmental conditions and pathogens during its migratory history after its divergence from the chicken.

\section{Background}

The genomic region of the major histocompatibility complex (Mhc) contains multi-gene family members involved in the immune response. The Mhc class I and class II genes encode glycoproteins that transport foreign peptides to the surface of cells for recognition by $\mathrm{T}$ cell receptors on lymphocytes, which in turn kill infected cells [1]. The Mhc class II molecules have highly polymorphic peptide binding regions (PBR) for the $\alpha 1$ and $\beta 1$ domains encoded by the class IIA and class IIB genes, respectively, in various vertebrates including avian [2]. These polymorphisms may have been generated by gene conversion and positive selection, such as balancing selection and overdominant selection to adapt to life-environmental pathogens $[3,4]$.

The most information currently available on the genomic organization of the Mhc in birds is for the chicken and quail. The chicken (Gallus domesticus) Mhc (Gado) region is divided into two major parts, Gado-B and Gado- $Y$ [5]. Both of these regions are inherited independently of each other, although they are physically linked on micro-chromosome 16 (GGA16), [6-9]. From previous genomic studies, GGA16 is suggested to be an essential immunity chromosome, which is composed of genes involved with adaptive immunity $(B F / B L$ segment in $G a d o-B)$, innate immunity (Gado-Y) and intrinsic immunity (TRIM-like and $B G$ gene segments in the extended Gado- $B$ region [[5,10-13], Shiina et al, Unpublished data].

The quail (Coturnix japonica, Coja) belongs to the same order (Galliformes) and family (Phasianidae) as the chicken. Whereas the quail is a migratory bird originating from Northern and Southern Asia, flying only short distances at a time and with a relatively short history of domestication, the chicken is a non-migratory bird originating from Southeastern Asia and with a thousand year history of domestication. Chicken - quail hybrids have been produced by artificial insemination of quails with chicken sperm [22]. Several immunological traits have been compared between various lines of quail which were selected for high and low IgY levels in the serum [23], and for high and low secondary antibody responses to Newcastle disease virus [24,25], influenza virus, sheep erythrocytes and Salmonella pullorum [26]. The quail is susceptible to Marek's disease virus as observed in the chicken. The chicken Gado-B complex has a significant influence in the genetics of disease resistance, such as Rous sarcoma and Marek's disease, but which genes within the complex are responsible and how they confer resistance or susceptibil- ity is not known [16-18]. One important obstacle to elucidating the Mhc resistance genes in chicken is that the $B F$, $B L$ and $B G$ genes have co-evolved as haplotypes with a high linkage disequilibrium between the genes due to the compact structure of its "minimal essential" Mhc [19-21]. However, the immune response against the Marek's disease tumor-associated surface antigen (MATSA) in the quail differs significantly from that in the chicken [27]. Such immunological differences are likely to be due in part to the number and variation in Mhc gene loci and/or alleles, but the data concerning the Coja haplotypes and their association with disease is largely lacking. From our previous transcription and genomic studies, we found that the quail and chicken Mhc regions have a similar overall organization, but differ markedly in that the quail has an expanded number of duplicated genes with 7 class I, 10 class IIB, 4 natural killer (NKr)-like receptor, 6 lectin-like receptor and $8 B G$ genes $[14,28,29]$. To explain these findings, haplotypic genome comparison among quails and between the quail and the chicken is a matter of primary importance to elucidate the gene organization, molecular mechanism of polymorphism generation and disease analysis.

In order to better understand the genetic factors involved in the generation of Mhc diversity in quail, we identified and characterized six CojaIIB haplotypes by genotyping and polymorphism analysis using expressed CojaIIB sequences. We determined the genomic sequences within the Tapasin-BRD2 genomic segment of five different Coja haplotypes including the major transcribed CojaIIBs. We also compared the quail Mhc class II genomic structures and diversities of the chicken $B 12$ and B21 haplotypic orthologs by phylogenetic analysis and duplication modeling. This study shows that the quail has much greater Mhc class IIB diversity and genomic structural flexibility than the chicken even though the two species are closely related in the evolutionary spectrum.

\section{Results and discussion Coja haplotype analysis with polymorphic loci}

Three polymorphic markers PM1, PM2 and PM3, (Table 1) were used to genotype 48 randomly selected quails. We chose these three markers for the preliminary classification of Coja haplotypes because they are located in the Tapasin, Coja-DBB1 and Coja-DMB2 loci, respectively (Figure 1). The allele frequencies and heterozygosities for the polymorphic markers are presented in Table 2 . All of the genotype frequencies were over $13 \%$ and the heterozygos- 
ity for each marker was over 0.65 . The minimum number of haplotypes predicted from the maximum likelihood analysis of the 48 quails by the two different methods, a Bayesian statistical method and an Expectation-Maximization (EM) algorithm, was six (Table 3). Of the six haplotypes, the haplotype numbers (HT1 to HT5 had higher frequencies, ranging from of $14.6 \%$ to $28.1 \%$, than HT6 (5.2\%). Interestingly, HT2 and HT6 had the same "6-10" and "*02" allele combinations at the PM1 and PM2 loci respectively, but a different allele type at the PM3 locus (Table 3).

On the basis of finding the different allele type at the PM3 locus in HT6, recombination happened at least once in the region within the $24.4 \mathrm{~kb}$ segment between the quail genes Coja-DBB1 and Coja-DMB2 (PM2-PM3) and the newly created haplotype has spread in the population. Future analyses using fully pedigreed families should help to ascertain whether the intervening segments of DNA are the same in different individuals with the same threemarker genotype. Nevertheless, the variability in the quail genomic segment between the Coja-DBB1 and Coja$\mathrm{DMB} 2$ genes corresponds to the chicken $\mathrm{BF} / \mathrm{BL}$ region that displays strong linkage disequilibrium and genomic structural stability $[19,20]$.

\section{Gene loci identification and haplotype reanalysis by $R T$ - $P C R, C D N A$ cloning and sequencing of transcribed CojallB} loci

In order to identify and characterize the transcript sequences expressed by the gene loci of the different haplotypes, six quails with relatively high HT frequencies representing haplotypes HT1 to HT5 were selected for RTPCR, cDNA cloning and sequencing analysis. The transcription intensity of the CojalIB genes was estimated from the number of clones sequenced. A summary of the transcription intensity results for the five haplotypes is presented in Table 4. The Table shows the transcription intensity for HT1 to HT5 as a percent frequency of the clones for each individual quail (identified as numbers $302,311,312,321,322$ and 323) with the percent frequency of clones per haplotype in parenthesis. The Table also shows the gene locus, the detected allele type, the PM2 allele, the nucleotide accession number in GenBank and the percent nucleotide similarity of the cDNA clones to the transcribed sequences expressed by the CojaIIB loci of HT1.

In total, 15 kinds of CojaIIB cDNA sequences derived from the RT-PCR products of six quails were identified by sequence comparison (Table 4). Another 19 CojaIIB sequences were previously reported $[14,25]$. Altogether, these expressed sequences were identified to be expressed either by loci that were previously described alphabetically as Coja-DAB1 to Coja-DGB1 for HT1 or by as yet unnamed loci. The new loci identified in this study were therefore given names, such as CojaII-01, CojaII-02, CojaII13 and CojaII-16 as listed in Table 4, using the naming formulae "CojaII-XX" as suggested by Shimizu et al [25] for the nomenclature of CojaIIB sequences. Each quail transcribed three to eight kinds of CojaIIB gene sequences (Table 4). Five to six of the cDNA sequences, which were observed in three quails $(302,312$ and 321), perfectly matched with six of the seven CojaIIB loci of Coja haplotype 1 (HT1), that is Coja-DAB1 and -DBB1 in the major class II region, and Coja-DCB1, -DEB1, -DFB1 and -DGB1 in the minor class II region [14]. However, no sequences were detected in our study for the HT1 Coja-DDB1 locus. In addition, two other cDNA sequences were tentatively named Coja-DFB1 ${ }^{*} 02$ in HT5 and Coja-DGB1*02 in HT1 because they appear to be additional alleles at the CojaDFB1 and -DGB1 loci, respectively, as determined from our phylogenetic analysis (Figs. 2, Table 4, Additional file 1 ). The sequences of CojaII-01, -02 and -04 were perfectly matched to the previously determined CojaII-01HL, $02 \mathrm{HL}$ and $-04 \mathrm{H}$ haplotype sequences (Accession numbers; $\mathrm{AB} 110476$ to $\mathrm{AB} 110478)$, respectively, which were derived from different inbred lines $[25,26]$. However, the CojaII-13,-14, -16 and -17 sequences did not have significantly high nucleotide similarities with the previously determined sequences $(76.3 \sim 88.9 \%)$ of HT1 sequences and, therefore, were assigned as belonging to other unique haplotypes (Table 4).

On the basis of the correlation of the Coja haplotypes and distribution of the transcribed CojallBs for each of the quails, the fifteen CojaIIB sequences were classified to five distinct Coja haplotypes, namely, HT1, consisting of Coja$D A B 1,-D B B 1,-D C B 1,-D E B 1,-D F B 1$ and -DGB1 loci; HT2, CojaII-13; HT3, CojaII-16 and -17; HT4, CojaII-01, 02 and -04; and HT5, Coja-DFB1 and CojaII-14 (Table 4). From the cDNA cloned frequencies per Coja haplotype, Coja-DAB1, -DBB1, CojalI-01, -13, -14, -16 and -17, excluding - $D A B 1$ in quail 321 , were the major transcribed CojaIIBs with cloned frequencies of $34.8 \sim 100 \%$, CojaII02 and -04 were moderately transcribed CojaIIBs with cloned frequencies of $19.1 \sim 29.4 \%$, and Coja-DCB1 $* 1$, $D E B 1 * 02, \quad-D F B 1{ }^{*} 01, \quad-D F B 1^{*} 02, \quad-D G B 1{ }^{*} 01$ and $D G B 1 * 02$ were minor transcribed CojaIIBs with cloned frequencies of $2.9 \sim 14.3 \%$ (Table 4 ). This result suggests that each Coja haplotype has at least one and up to seven transcribed CojaIIB loci with one or two of them representing the major locus.

\section{Genomic diversity of Tapasin-BRD2 segment}

The Tapasin-BRD2 genomic segment contains the major CojaIIB region with the Coja-DAB1, Coja-DBB1 and the Coja-Lec1 genes flanked by the Tapasin and the BRD2 genes. This segment also has the PM1 and PM2 markers that we used for haplotyping. In order to study the 
Table I: Basic features of the three polymorphic markers on Coja region

\begin{tabular}{|c|c|c|c|c|c|c|c|}
\hline \multirow[b]{2}{*}{$\begin{array}{c}\text { marker } \\
\text { name }\end{array}$} & \multicolumn{3}{|c|}{ Coja haplotype I (Acc. Num. AB078884) } & \multirow[b]{2}{*}{ range (bp) } & \multirow[b]{2}{*}{ polymorphisms } & \multirow[b]{2}{*}{ primer name } & \multirow[b]{2}{*}{ primer sequence $\left(5^{\prime}\right.$ to $\left.3^{\prime}\right)$} \\
\hline & Nuc. position** & Gene position & $\begin{array}{l}\text { length } \\
\text { (bp) }\end{array}$ & & & & \\
\hline \multirow[t]{2}{*}{ PMI } & $89043-89887$ & Tapasin (ex.4 - int.4) & 845 & $718-1095$ & $\begin{array}{c}\text { (ATGAT)n } \\
\text { (TTCCTATGGGGGCTGTA } \\
\text { GGGTGGATGGGACTGGG } \\
\text { TGGTA)n }\end{array}$ & TAPBPL-F & CAGGTCCTGCTGGCCTATGA \\
\hline & & & & & & TAPBPL-R & TGGTGTGATGCCAACCCAT \\
\hline \multirow[t]{2}{*}{ PM2 } & $92768-93787$ & $\begin{array}{c}\text { Coja-DBBI } \\
\text { (Promoter - ex.3) }\end{array}$ & 1002 & $989-1002$ & 126 SNPs, 13 indels & $\begin{array}{c}\text { CojaDBBpromoter } \\
\text { F6 }\end{array}$ & CCCTGGGGACACCATTTGTCAT \\
\hline & & & & & & C2BNO5 & GCGCCAGGAAGACGAGCCCCAGCAC \\
\hline \multirow[t]{2}{*}{ PM3* } & $118204-118536$ & DMB2 (int.I - int.2) & 333 & 333 & $\mathrm{G} / \mathrm{A}, \mathrm{G} / \mathrm{C}$ & DMB2-F & GGAGTGCATCCCCATTGCT \\
\hline & & & & & & DMB2-R & GCTCACTCTTGCGCAGTGC \\
\hline
\end{tabular}

* PM3 contains two SNP sites.

** positions on Coja haplotype I genomic sequence (accession number; AB078884).

genomic diversity of the Tapasin-BRD2 segments in different haplotypes by genomic sequencing, two cosmid libraries were constructed representing the haplotypes HT2, HT3, HT4 and HT5.

The average insert sizes of cosmid libraries constructed from the genomic DNA of quails 311 (HT 2/3) and 322 (HT 4/5) were estimated to average $37.5 \mathrm{~kb}$ and $44.6 \mathrm{~kb}$, respectively, by $0.3 \%$ agarose gel electorophoresis analysis using 20 randomly selected cosmids (data not shown). As the quail has a genome size of $1.2 \times 10^{9} \mathrm{bp}$, similar to the chicken, the two cosmid libraries 311 and 322 were expected to cover $2.5 \times 10^{10} \mathrm{bp}$ (20.9-fold) and $21.4 \times$ $10^{10}$ bp (17.8-fold), respectively [11]. Two Tapasin (clone number: 311CIIB-18 and 311CIIB-20) and two BRD2 positive cosmids (322CIIB-01 and 322CIIB-02) were isolated from HTs $2 / 3$ and HTs $4 / 5$ cosmid libraries, respectively. DNA typing revealed that the CojaIIB genes within the cosmids 311CIIB-18, 311CIIB-20, 322CIIB-01 and 322CIIB-02 corresponded to the haplotypes HT2, HT3, HT5 and HT5, respectively. Therefore, we selected the cos- mids 311CIIB-1 8 (HT2), 311CIIB-20 (HT3) and 322CIIB02 (HT5) for the genomic sequencing study of the Tapasin-BRD2 segment.

The genomic sequences derived from 311CIIB-18, 311 CIIB-20 and 322CIIB-02 cosmids were determined by the shotgun method. Also a part of the Tapasin-BRD2 segment was sequenced from the long-ranged PCR products amplified from the genomic DNA of HT3 and HT4 homozygote quails $[25,26]$. The genomic structures of the major transcribed MhcIIB segments within the 5 quail haplotypes $\mathrm{H} 1$ to $\mathrm{H} 5$ and the chicken haplotype $\mathrm{B12}$ derived from the genomic sequencing information and transcript alignments are shown in Fig. 3. The dot-matrix analyses between the 5 Coja haplotypes, chicken and quail, and two chicken haplotypes are shown in Additional file 2. After sequencing, the nucleotide lengths of the segment between the Tapasin-BRD2 genes were determined to be 5,984 bp in HT2, 16,462 bp in HT3, 5,222 bp in HT4 and 5,840 bp in HT5. The sequence of four segments on HT3 and HT4 was not determined fully how-

Table 2: Genotype frequency and heterozygosity for three markers

\begin{tabular}{|c|c|c|c|c|c|}
\hline marker & Allele & length (bp) & Nt. Acc, No. & Frequency (\%) & Heterozygosity \\
\hline \multirow[t]{5}{*}{ PMI } & $9-12$ & 845 & AB282647 & 28.1 & 0.794 \\
\hline & $6-10$ & 718 & AB282648 & 22.9 & \\
\hline & $8-12$ & 806 & AB282649 & 13.5 & \\
\hline & $10-14$ & 900 & $A B 282650$ & 20.8 & \\
\hline & $18-14$ & 1095 & AB28265I & 14.6 & \\
\hline \multirow[t]{5}{*}{ PM2 } & $* 01$ & 1002 & AB282652 & 28.1 & 0.794 \\
\hline & $* 02$ & 1001 & AB282653 & 22.9 & \\
\hline & $* 03$ & 989 & AB282654 & 13.5 & \\
\hline & $* 04$ & 1001 & $A B 282655$ & 20.8 & \\
\hline & $* 05$ & 989 & AB282656 & 14.6 & \\
\hline \multirow{3}{*}{ PM3 } & G-C & 333 & $A B \mid 86377$ & 28.1 & 0.650 \\
\hline & G-G & 333 & $A B \mid 86378$ & 45.8 & \\
\hline & $A-C$ & 333 & $A B \mid 86379$ & 26.0 & \\
\hline
\end{tabular}


Table 3: Summary of Coja haplotypes (HTI-6) and their frequencies

\begin{tabular}{|c|c|c|c|c|c|}
\hline HT num. & PMI & PM2 & PM3 & Obs. Num. & Freq. (\%) \\
\hline I & $9-12$ & $* 0 \mathrm{I}$ & G-C & 27 & 28.1 \\
\hline 2 & $6-10$ & $* 02$ & G-G & 17 & 17.7 \\
\hline 3 & $8-12$ & *03 & G-G & 13 & 13.5 \\
\hline 4 & $10-14$ & $* 04$ & $A-C$ & 20 & 20.8 \\
\hline 5 & $18-14$ & $* 05$ & G-G & 14 & 14.6 \\
\hline 6 & $6-10$ & $* 02$ & $A-C$ & 5 & 5.2 \\
\hline
\end{tabular}

Bold letter shows Coja haplotype frequency with over $10 \%$.

ever, for DNA structural reasons, such as the difficulties encountered with long repeat sequences and extremely high GC contents (Figs. 3, Additional file 2).
The Tapasin-BRD2 segment showed extremely complicated genome structures among the Coja haplotypes examined, similar to the $H L A-D R$ region in the human

Quail Mhc ( Coja ) region (AB078884)

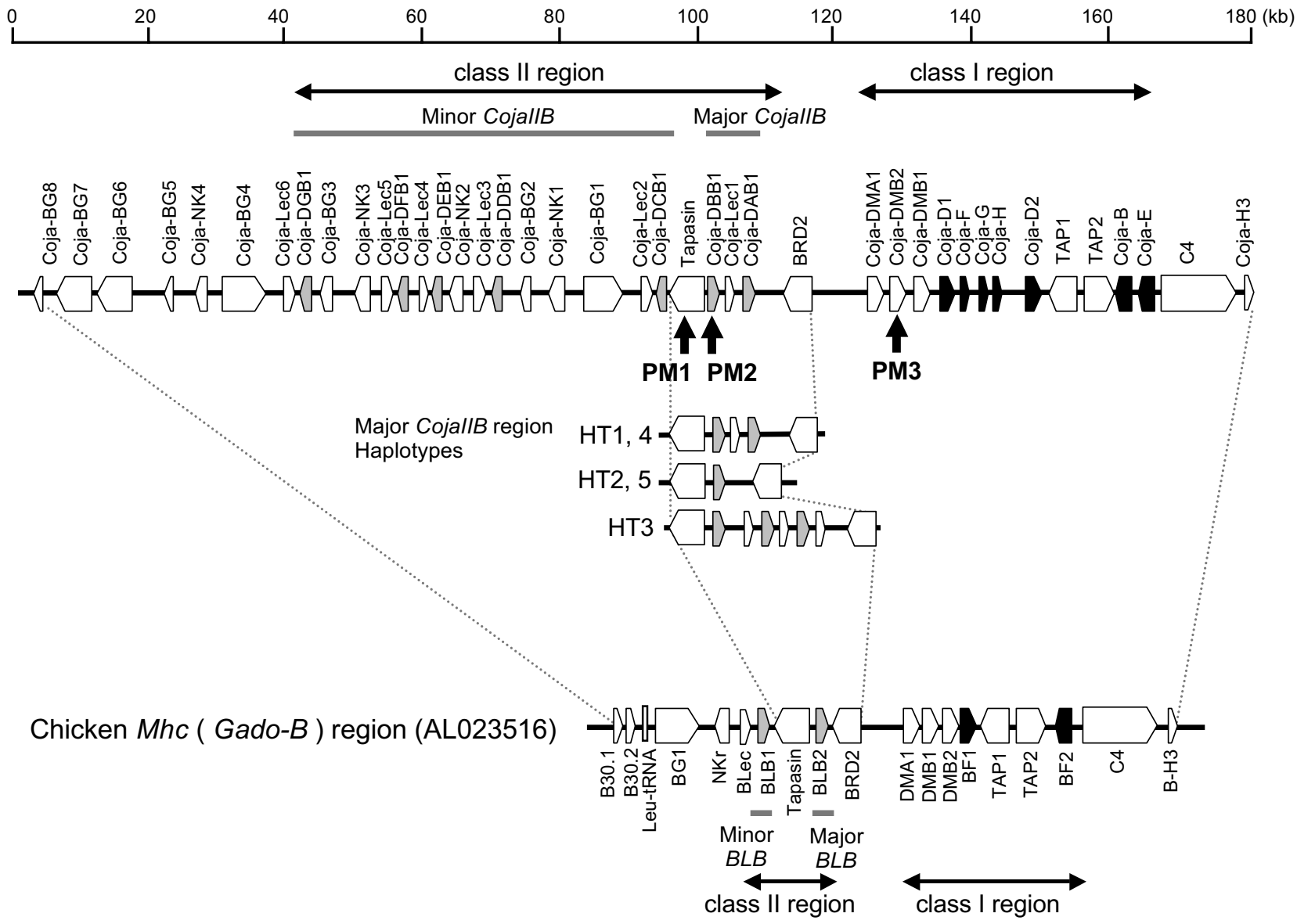

\section{Figure I}

Comparative gene map of quail and chicken Mhc region and locations of the genetic markers PMI to PM3. The map shows the comparison of the $180 \mathrm{~kb}$ Coja haplotype I sequence (AB078884: Shiina et al 2004) and the $92 \mathrm{~kb}$ chicken B/2 haplotype sequence (AL0235 16: Kaufman et al 1999). Black and gray boxes indicate the Mhc class I and class IIB loci respectively. White boxes indicate other genes. The labeled vertical arrows indicate the locations of the newly designated genetic markers PMI - PM3. 
Table 4: Percent frequency of cloned cDNA, distribution and classification of the transcribed CojallB allele as five distinct Coja haplotypes

\begin{tabular}{|c|c|c|c|c|c|c|c|c|c|c|c|}
\hline \multirow[t]{3}{*}{$\begin{array}{c}\mathrm{HT} \\
\text { number }\end{array}$} & \multirow[t]{3}{*}{ Locus } & \multirow[t]{3}{*}{ Allele } & \multirow[t]{3}{*}{ PM2 alleles } & \multirow[t]{3}{*}{$\begin{array}{l}\text { Nt. Acc, } \\
\text { No. }\end{array}$} & \multirow{3}{*}{$\begin{array}{l}\text { Nucleotide } \\
\text { similarity to } \\
\text { HTI (\%) }\end{array}$} & \multicolumn{6}{|c|}{$\begin{array}{c}\% \text { frequency of cDNA clones per individual quail (\% frequency of cDNA clones per } \\
\text { haplotype) }\end{array}$} \\
\hline & & & & & & \multicolumn{6}{|c|}{ quail individual number } \\
\hline & & & & & & $302 *$ & 311 & 312 & 321 & 322 & 323 \\
\hline \multirow[t]{8}{*}{ HTI } & Coja-DABI & $\begin{array}{c}\text { Coja- } \\
D A B I * 0 I\end{array}$ & & $A B|8| 86 I$ & 100 & $\begin{array}{l}46.9 * * \\
(46.9)^{* * * *}\end{array}$ & - & I7.I (37.1) & $5.9(19.0)$ & - & - \\
\hline & Coja-DBBI & $\begin{array}{c}\text { Coja- } \\
D B B I * 0 I\end{array}$ & $\begin{array}{c}\text { Coja- } \\
D B B I * 0 I\end{array}$ & $A B|8| 862$ & 100 & $35.9(35.9)$ & - & $22.4(48.6)$ & $16.2(52.4)$ & - & - \\
\hline & Coja-DCBI & Coja-DCBI*0I & & $A B \mid 81863$ & 100 & $6.3(6.3)$ & - & I.3 (2.9) & $2.9(9.5)$ & - & - \\
\hline & Coja-DDBI & - & & - & - & - & - & - & - & - & - \\
\hline & Coja-DEBI & Coja-DEBI*0I & & $A B|8| 865$ & 100 & $4.7(4.7)$ & - & $2.6(5.6)$ & - & - & - \\
\hline & Coja-DFBI & Coja-DFBI*0I & & $A B 181866$ & 100 & - & - & $1.3(2.9)$ & I.5 (4.8) & - & - \\
\hline & Coja-DGBI & Coja-DGBI*0I & & $A B \mid 81868$ & 100.0 & $6.3(6.3)$ & - & - & $4.4(14.3)$ & - & - \\
\hline & Coja-DGBI & Coja-DGBI $* 02$ & & $A B 181869$ & 98.9 (DGBI) & - & - & $1.3(2.9)$ & - & - & - \\
\hline $\mathrm{HT} 2$ & Cojall-13 & Cojall-I3*0I & $\begin{array}{c}\text { Coja- } \\
D B B I * 02\end{array}$ & $A B|8| 874$ & $\begin{array}{l}76.3(\mathrm{DCBI}) \sim \\
87.4(\mathrm{DABI})\end{array}$ & - & $62.9(100)$ & $53.9(100)$ & - & - & $67.2(100)$ \\
\hline \multirow[t]{2}{*}{ HT3 } & Cojall-16 & Cojall-I6*0I & $\begin{array}{c}\text { Coja- } \\
D B B I * 03\end{array}$ & AB26428I & $\begin{array}{l}78.9(\mathrm{DCBI}) \sim \\
85.2(\mathrm{DBBI})\end{array}$ & - & $12.9(34.8)$ & - & - & - & - \\
\hline & Cojall-I 7 & Cojall-I7*0I & & AB264282 & $\begin{array}{l}77.5(\mathrm{DCBI}) \sim \\
83.3(\mathrm{DGBI})\end{array}$ & - & $24.2(65.2)$ & - & - & - & - \\
\hline \multirow[t]{3}{*}{ HT4 } & Cojall-02 & Cojall-02*0I & $\begin{array}{c}\text { Coja- } \\
D B B I * 04\end{array}$ & $A B|8| 87 \mid$ & $\begin{array}{l}78.1(\mathrm{DCBI}) \sim \\
88.9(\mathrm{DBBI})\end{array}$ & - & - & - & $13.2(19.1)$ & I $4.5(29.4)$ & - \\
\hline & Cojall-0I & Cojall-0I*0I & & $A B \mid 81870$ & $\begin{array}{l}78.9(\mathrm{DCBI}) \sim \\
87.8(\mathrm{DBBI})\end{array}$ & - & - & - & $36.8(53.2)$ & $21.7(44.1)$ & - \\
\hline & Cojall-04 & Cojall-04*0I & & $A B|8| 872$ & $\begin{array}{l}77.8(\mathrm{DCBI}) \sim \\
84.4(\mathrm{DBBI})\end{array}$ & - & - & - & 19.1 (27.7) & $13.0(26.5)$ & - \\
\hline \multirow[t]{4}{*}{ HT5 } & Cojall-14 & Cojall- $\mid 4 * 0 I$ & $\begin{array}{c}\text { Coja- } \\
D B B I * 05\end{array}$ & $A B \mid 81876$ & $\begin{array}{l}77.4(\mathrm{DCBI}) \sim \\
87.4(\mathrm{DABI})\end{array}$ & - & - & - & - & $47.8(94.3)$ & $28.1(85.7)$ \\
\hline & Coja-DFBI & Coja-DFBI*02 & & $A B \mid 81867$ & 99.3 (DFBI) & - & - & - & - & $2.9(5.7)$ & $4.7(14.3)$ \\
\hline & $\begin{array}{l}\text { cDNA sub- } \\
\text { clone }\end{array}$ & & & & & 64 & 62 & 76 & 68 & 69 & 64 \\
\hline & $\begin{array}{c}\text { Presumptive } \\
\text { HT }\end{array}$ & & & & & $1 / 1$ & $2 / 3$ & $1 / 2$ & $1 / 4$ & $4 / 5$ & $2 / 5$ \\
\hline
\end{tabular}

Bold letter indicates sub-clone frequency over $30 \%$. (-) means not transcribed. Coja-DFBI*02 was categorized to "HT5" because this allele sequence was observed in only HT5.

MHC genomic region (Figs. 3, Additional file 1) [31]. The Tapasin-BRD2 segment of HT2 and HT5 contained only one major transcribed CojaIIB (CojaII-13 and -14, respectively) and their genomic structures and nucleotide length were similar to the chicken orthologous $B L$ region (Figs. 3, Additional file 1). The Tapasin-BRD2 segment of HT1 contained two major transcribed CojaIIBs (Coja-DAB1 and DBB1) (Fig. 3) [13]. Similarly, the Tapasin-BRD2 segment of the HT4 contained two CojaIIBs (CojaII-01 and CojaII02 ) with major and moderately transcribed CojaIIB genes (Table 4). In HT3, the Tapasin-BRD2 segment contained three CojaIIBs, CojaII-16, Coja-W1 and Coja-W2. The CojaII-16 is a major transcribed CojaIIB, but although both Coja-W1 and -W2 have intact structures their mRNA was not obtained from the peripheral blood cells (Fig. 3). In all of the major transcribed CojaIIBs, the nucleotide length of intron 1 was variable whereas the other introns were relatively well conserved (Table 5). Moreover, one major transcribed CojaIIB (CojaII-17) that was observed in the HT3 (Table 4) was not identified in the Tapasin-BRD2 segment (Additional file 1). Consequently, the CojaII-17 is the only gene that either locates to a minor transcribed CojaIIB locus or to some other genomic region.

In summary, the Tapasin-BRD2 segment contains one or two major transcribed CojaIIBs that were identified in this study in much the same way as the chicken with its major transcribed MhcIIB, BLB2 (Figs. 1, 3). In contrast to Xenopus and mammals that also have MhcIIB genes located within the Tapasin-BRD2 segment, the bony fishes, such as medaka, fugu and rainbow trout, have MhcI genes within the Tapasin-BRD2 segment. Thus, the locations of the major transcribed CojaIIBs and BLB2 are well conserved in birds and more comparable with mammals and reptiles than with bony fish from the point of view of evolution [15,32-34].

\section{Molecular evolutionary analysis of the chicken and quail MhcllB genomic region}

In a comparison of the CojaIIB gene organization of different haplotypes, the CojaIIB genomic units in the TapasinBRD2 segment of the HT1 [DBB1 - Lec - DAB1] and HT4 [CojaII-02 - Lec - CojaII-01] were noted to resemble the 


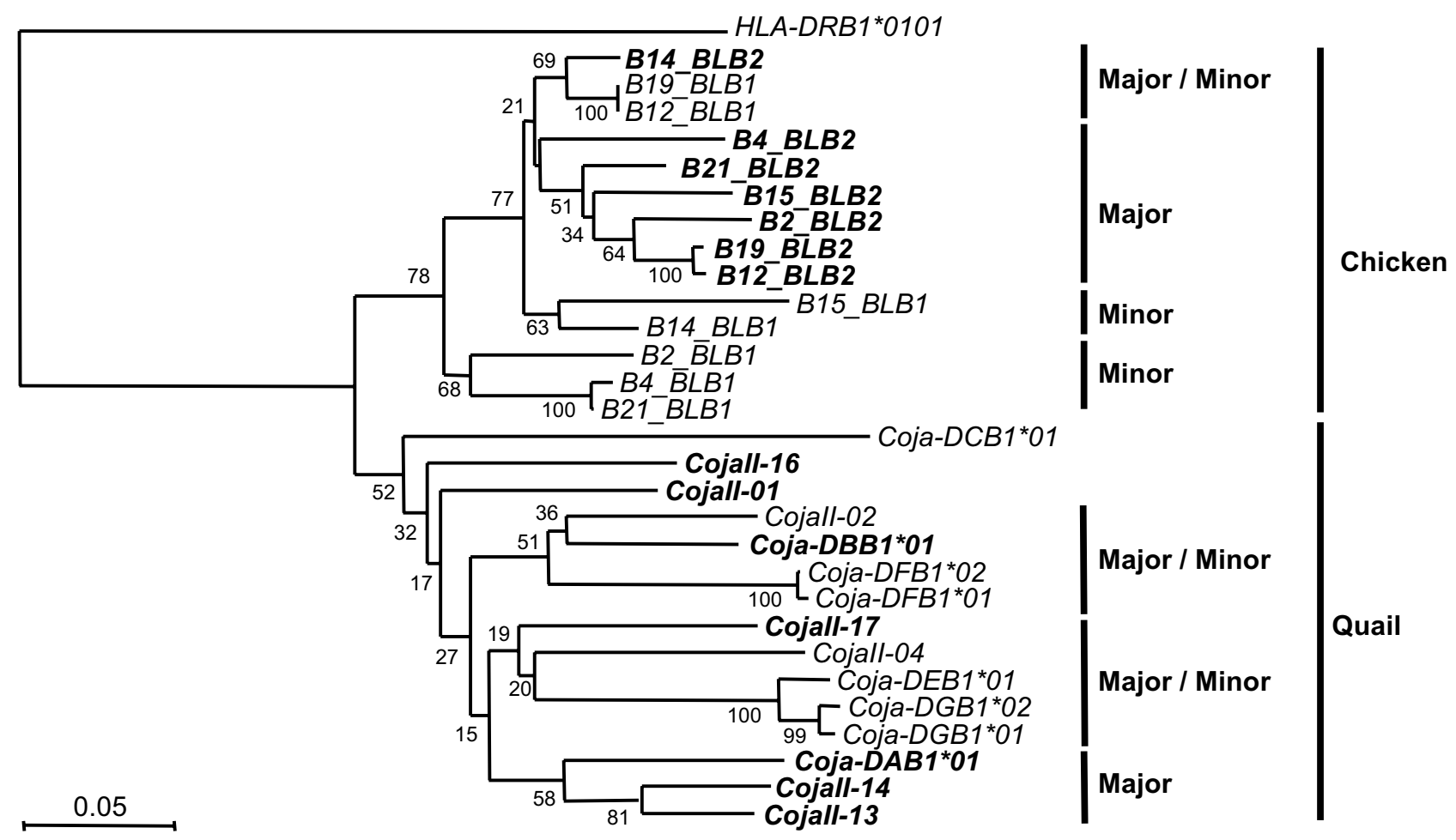

Figure 2

Phylogenetic tree of the quail and chicken transcribed MhcllBs. The dendrogram was constructed from the nucleotide sequences of the $\beta I$ extracellular domain regions (exon 2) (270 nucleotides in length) of MhcllB genes for the I6 CojallBs shown in figure SI the chicken haplotypic $B L B$ sequences on $B 2 B 4 B / 2$ B/ 4 B/5 B 9 and B2I (AJ248576 AJ248583 AJ248572 AJ24858I AJ248585 AJ248577 AJ248584 AJ248579 AJ248580 AJ248582 AJ248574 AJ248586 AJ248575 and AJ248573) and HLA-DRBI (AFI42457). The HLA-DRBI sequence used as a species outlier roots the tree. Values near the branch-points of the tree indicate the bootstrap values. Bold letters indicate major transcribed CojallBs and BLBs.

minor CojaIIB genomic DFB1/DEB1 unit [DFB1 - Lec4 DEB1], whereas those of the HT3 [CojaII-W2 - Lec CojaII-W1 - Nkr - CojaII-16] resemble the DFB1/DEB1/ DDB1 unit [DFB1 - Lec4 - DEB1 - NK2 - (Lec3) - DDB1], although they are in the opposite direction to each other (Fig. 3). Thus, two kinds of successive trans-segmental duplications involving non-Mhc genes appear to have produced the major CojaIIB segments independently. However, significant nucleotide homologies between the duplicated units were not observed (data not shown). Since comparable segmental duplication variability has not been observed in the Gado-B region, the trans-segmental duplications in quail are likely to have occurred after speciation of the quail and chicken from their common ancestor. In the case of human $M H C$, the traits of segmental duplications and transpositions were observed in the HLA class I region [35], and especially the generation of the $H L A-B$ and $-C$ segment that is explained by the events involving the MHCI, MIC, HCGII, HCGIV, HCGIX, HCP5, 3.8-1 unit in the evolutionary process [36].
To clarify the genetic relationships among the CojaIIB sequences and between the quail and the chicken MhcIIB sequences, a phylogenetic tree of exon 2 was constructed (Fig. 2). This tree suggests that the CojaIIB gene sequences are more closely related to each other in the quail than to the chicken MhcIIB (BLBs), and that the CojaIIB genes have been duplicated after speciation of quail and chicken. The average genetic distance of the CojaIIB sequences $(0.194+0.018)$ after speciation is twice as long as that of the $B L B$ sequences $(0.107+0.016)$, meaning that the CojaIIB genes have a relatively faster evolutionary speed than the BLBs (Fig. 2). On the other hand, chicken haplotype sequences are more closely related. From the genome sequencing of the Red Jungle Fowl Mhc region, the $B L B$ nucleotide sequences were perfectly matched with domestic chicken $B 21^{*} B L B 1$ and $B 21^{*} B L B 2$ sequences [Shiina et al, Unpublished data]. Therefore, the $B L B$ genes appear to have been generated from a recent common ancestor of both the egg-laying domestic chicken and broilers. 


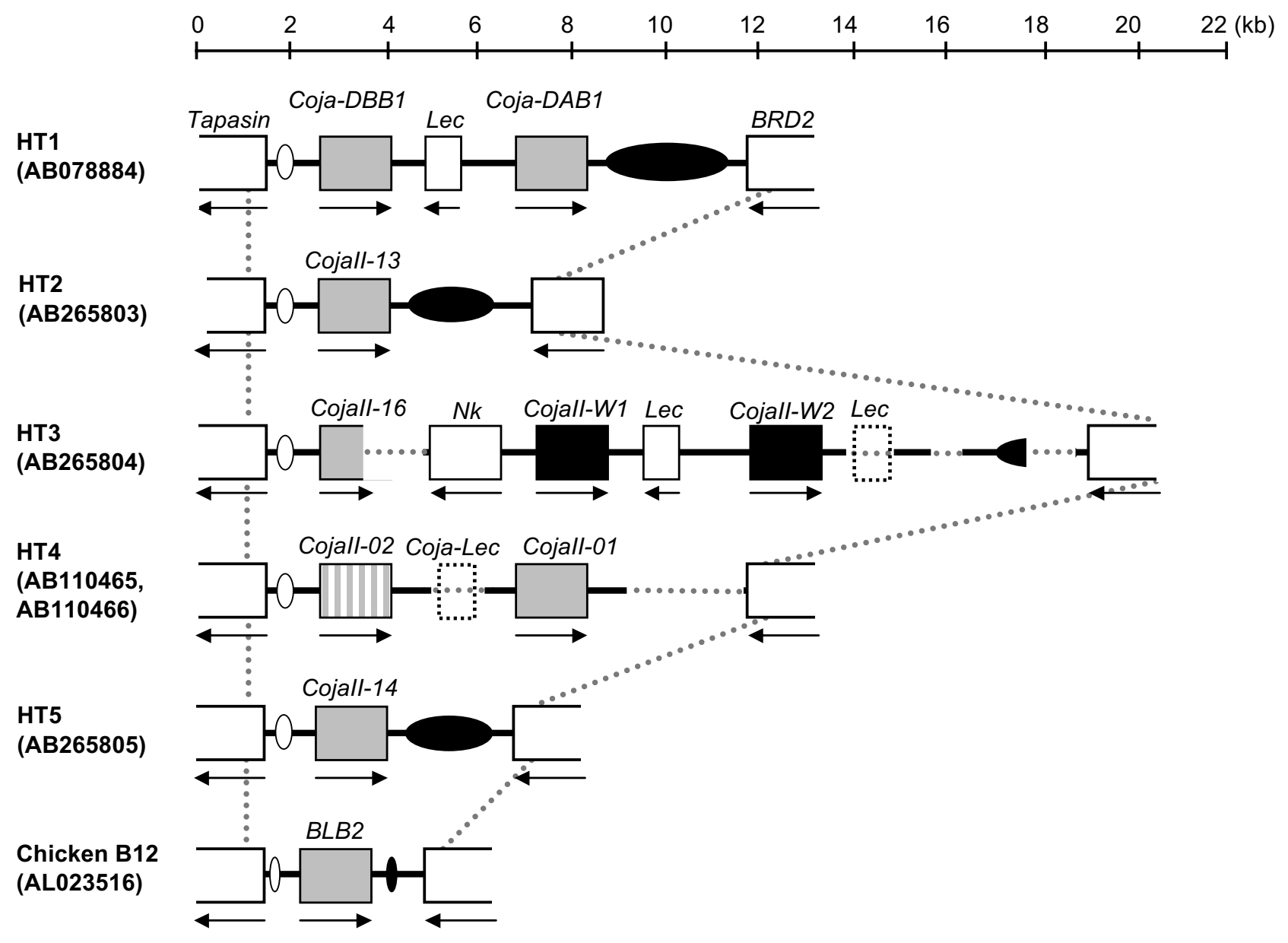

Figure 3

Genomic structures of the major transcribed MhcllB segments in the quail and chicken. The map shows the comparison of the major transcribed MhcllB segments on five Coja haplotypic sequences (HTI HT2 HT3 HT4 and HT5) and the chicken $B / 2$ haplotype sequence. Gray striped and black boxes indicate the major transcribed MhcllB moderately transcribed MhcllB and non-transcribed MhcllB respectively. White boxes indicate other genes. The numbers in parenthesis are the GenBank accession numbers. The white oval indicates TBI and the black oval indicates the location of TB2-I TB2-2 and TB3.

In the phylogenetic tree, the quail lineage was divided into three main clusters, one major and two major/minor intermingled clusters, with the Coja-DCB1*01, CojaII-01 and CojaII-16 out-grouped from the three main clusters. In comparison, the chicken lineage was divided into four main clusters, namely one major, two minors and one major/minor intermingled cluster (Fig. 2). In the case of the major transcribed CojaIIBs, these were observed in all clusters. In addition, the traits for two kinds of segmental duplications were observed in the Tapasin-BRD2 segment as previously mentioned, suggesting that the major transcribed CojaIIBs were generated by independent duplications and/or transpositions between the major and minor CojaIIB segments at a relatively high evolutionary speed after the separation of the quail and chicken from their common ancestor (Fig. 4). In contrast, the BLB2 sequences of extant chickens appear to have been generated from an ancestral BLB2 gene with very little structural reorganization or change (Fig. 4).

\section{Genomic rearrangement elements in the major CojallB segment involved in the generation of Mhc diversity} Four types of tandem repeat sequences were identified that possibly drive genomic rearrangement events within the Tapasin-BRD2 segment of HT1, HT2, HT3 and HT5 (Table 6). These simple candidate rearrangement elements are TB1, a known T-cell factor motif; TB3 and TB3, STRs found in the mouse Mhc class II region; and TB4, a recombination motif [37-39]. From the comparison of the repeat numbers of the solitary repeat unit between 
Table 5: Comparison of nucleotide length of intron and exons among CojallB in the Tapasin-BRD2 segment

\begin{tabular}{|c|c|c|c|c|c|c|c|}
\hline \multirow{2}{*}{$\begin{array}{c}\text { Coja HT } \\
\text { CojallB PM2 alleles }\end{array}$} & \multicolumn{2}{|r|}{ HTI } & \multirow{2}{*}{$\frac{\mathrm{HT2}}{\text { Cojall- I } 3 \text { Coja-DBBI*02 }}$} & \multirow{2}{*}{$\frac{\mathrm{HT3}}{\text { Cojall-I6 Coja-DBBI*03 }}$} & \multicolumn{2}{|r|}{ HT4 } & \multirow{2}{*}{$\begin{array}{c}\text { HT5 } \\
\text { Cojall- /4 Coja-DBBI*05 }\end{array}$} \\
\hline & Coja-DABI & Coja-DBBI Coja-DBBI*0I & & & Cojall-0I & Cojall-02 Coja-DBBI*04 & \\
\hline exonl & 91 & 91 & 91 & 91 & 91 & 91 & 91 \\
\hline intron I & 30 & 88 & 88 & 76 & 146 & 88 & 76 \\
\hline exon2 & 270 & 270 & 270 & 270 & 270 & 270 & 270 \\
\hline intron2 & 86 & 86 & 86 & 86 & 86 & 86 & 86 \\
\hline exon3 & 282 & 282 & 282 & 282 & 282 & 282 & 282 \\
\hline intron3 & 95 & 95 & 95 & 95 & 95 & 95 & 95 \\
\hline exon4 & 111 & 111 & 111 & 111 & 111 & 111 & 111 \\
\hline intron4 & 76 & 76 & 76 & 76 & 76 & 77 & 76 \\
\hline exon5 & 24 & 24 & 24 & 24 & 24 & 24 & 24 \\
\hline intron5 & 73 & 86 & 73 & 73 & 73 & 73 & 73 \\
\hline exon6 & 14 & 14 & 14 & 14 & 14 & 14 & 14 \\
\hline total & 1152 & 1223 & 1210 & 1198 & 1268 & 1211 & 1198 \\
\hline
\end{tabular}

quail and chicken, the Coja haplotypes were found to contain numerous repeat numbers for TB1 to TB4, whereas the chicken $B 12$ and $B 21$ haplotypes were found to have none or only a few repeat numbers (Table 6). The TB repeats were not identified in the minor transcribed CojaIIB segment of the HT1 genome contigs [14]. Therefore, the TB repeats appear to be rearrangement elements within the genome that provide strong driving forces for the generation of new major transcribed CojalIBs via duplications and/or transpositions.

\section{Genomic diversity within the major CojallB region and disease studies}

Mhc diversity in vertebrates is often attributed to the high SNP content in this genomic region. The generation of nucleotide polymorphism of Mhc genes is usually explained by positive selection, such as balancing selection and overdominant selection acting on the Mhc genes, which is necessary to maintain polymorphisms for survival against infections $[3,4]$. These selected pressures also lead to a hitch-hiking effect that results in the accumulation of many additional SNPs around the Mhc gene [30]. Namely, the DNA segments affected by hitch-hiking have arisen due to the accumulated effect of overdominant selection and balancing selection. In the HLA region, HLA-A, $-B,-D R / D Q$ and $-D P$ are thought to have been affected by hitch-hiking and associated with several diseases, such as IDDM, rheumatoid arthritis and psoriasis vulgaris $[30,40]$. The hitch-hiking effect was also observed in Gado-B region [Shiina et al, Unpublished data]. Because the CojaIIBs have developed at a faster evolutionary speed than the BLBs (Fig. 2), the CojaIIB region is likely to be also effected by hitch-hiking. If a harmful variation is generated around the Mhc gene via the hitch-hiking effect, then it is likely to be selected against by genetic recombination.
A serious problem for disease mapping in the Gado- $B$ region is that genetic recombination within the $B F, B L$ and $B G$ loci is rarely observed under experimental conditions, Therefore, Gado-B haplotypes encompassing alleles in all three loci are the units of inheritance most often considered in relating the Gado-B complex to immunity and disease responses [5]. On the other hand, the quail appears to be relatively more resistant than the chicken to many viral diseases [41]. In addition, the quail is thought to play an important role in the evolution of influenza viruses by acting as an intermediate host in which avian influenza viruses can be amplified and transmitted to other animal species [42]. Since the Coja region has the duplication and divergence of CojaIIBs (Figs. 2, 3, Additional file 1), the Coja region may be a superior system for the selection of beneficial variations enabling more antigen presentation ability than the Gado-B region. Therefore, to identify the disease genetic factors associated with the Gado- $B$ region, comparative genomic and disease mapping analysis of the Coja region is also important.

\section{Conclusion}

In conclusion, we characterized the genetic and genomic features of the CojaIIB region and obtained the following three main findings. Firstly, one to six transcribed CojaIIB loci were identified in each Coja haplotype, of which one or two of them was the major coding locus. The major CojaIIB genes, except for CojaII-17 of HT3, were located within the Tapasin-BRD2 segment. In contrast to the quail, the chicken has one major and one minor MhcIIB. Secondly, phylogenetic and evolutionary analyses suggest that the major transcribed CojaIIBs were organized by independent trans-segmental duplications involving nonMhc genes and/or transpositions between major and minor CojaIIBs. Consequently, the CojaIIBs have a relatively faster evolutionary speed than the BLBs. In contrast 


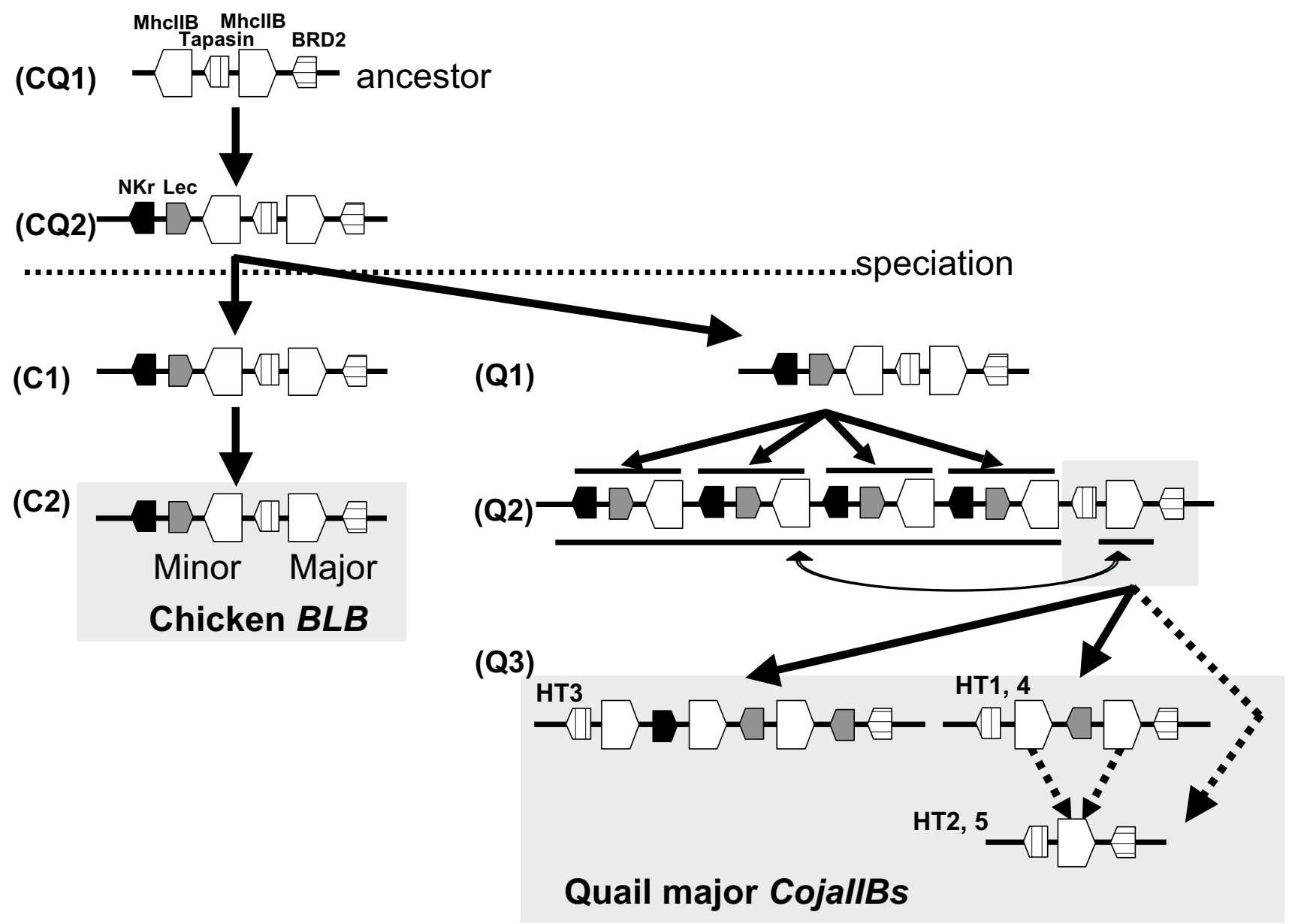

Figure 4

Gene duplication models inferred from the reconstructed phylogenetic trees. The labeled arrows indicate the speciation and gene duplication events for the chicken $(C)$ and quail $(\mathrm{Q})$ lineages. Dotted arrows indicate the evolutionary process for the origin of HT2 and HT5. Gray backgrounds indicate quail and chicken MHCIIB structures at the present-day.

to the quail, the chicken $B L B 2$ alleles have been generated from the ancestral $B L B 2$ probably since the separation of chickens and quails from their common ancestor. Thirdly, four types of genome rearrangement elements (remodeling repeats) composed of tandem repeats were identified within the $4 \sim 11 \mathrm{~kb}$ haplotypic Tapasin-BRD2 segment, and the quail has far more repeat numbers for rearrangement events than the chicken that displays strong linkage disequilibrium [19-21]. Taken together, these three main findings support the view that the genomic diversity of the CojaIIB region has been generated by duplications and gene transpositions via the candidate rearrangement elements along with a fast evolutionary speed in adapting to environmental conditions and pathogens during the migratory history of the quail after its divergence from the chicken. It is evident from our study that the quail MhcIIB region has a much more flexible genomic structure than the chicken for generating greater Mhc diversity.

\section{Methods \\ Quail}

Blood samples were collected from 48 randomly selected quails maintained at the Tokyo University of Agriculture $[23,43]$. The blood collection and animal studies were conducted in accordance with the Guidelines for Animal Experiments at the Tokyo University of Agriculture.

\section{Genotyping and haplotype analyses}

Three polymorphic markers, PM1 to PM3, were identified in the Mhc classIIB genomic region of the quail (Figure 1) and were used as markers in this study for an initial haplotype analysis [14] (Tables 1, 2) either by PCR and sequence based typing or by PCR and RFLP analysis. PM1 is a mini-satellite marker composed of two different types of repetitive sequences and located in the Tapasin gene; PM2 is Coja-DBB1 locus genotyping marker; and PM3 is composed of two SNP markers located within the Coja- 
Table 6: Candidate rearrangement elements (TB I-4) identified within the Tapasin-BRD2 segment

\begin{tabular}{|c|c|c|c|c|c|c|c|c|}
\hline \multirow[t]{2}{*}{ Name } & \multirow[t]{2}{*}{ Features and sequence of repeat unit } & \multicolumn{5}{|c|}{ Quail } & \multicolumn{2}{|c|}{ Chicken } \\
\hline & & $\mathrm{HTI}$ & $\mathrm{HT} 2$ & HT3 & HT4 & HT5 & $B / 2$ & B2I \\
\hline & TCF-I [37] & & & & & & & \\
\hline \multirow[t]{2}{*}{ TBI } & MAMAGn & $13^{*}$ & 13 & 26 & 27 & 23 & 3 & 3 \\
\hline & STRs in $\mathrm{H}-2$ class II region [38] & & & & & & & \\
\hline TB2 & CAGA $^{n}$ & 86 & 54 & $>14$ & Un & 56 & 5 & 5 \\
\hline \multirow[t]{2}{*}{ TB3 } & CAGGn & 120 & 75 & $>21$ & Un & 99 & 6 & 6 \\
\hline & Recombination hotspot motif [39] & & & & & & & \\
\hline \multirow[t]{2}{*}{ TB4 } & GGGCAGGARGn & 9 & 4 & $>1$ & Un & 5 & I & 1 \\
\hline & Total & 228 & 146 & $>62$ & $>27$ & 183 & 15 & 15 \\
\hline
\end{tabular}

* number of repeat units.

DMB2 gene (Table 1). Five different PM1 alleles were first identified by sequencing and then correlated with the length of their PCR products. The PCR product sizes of the PM1 alleles were then used to identify and define the alleles in the individual samples without the need for further sequencing. The PM1 alleles were designated as "6-10", "8-12", "9-12", "10-14" and "18-14" based on the length of the repeat units. For example, the "6-10" allele corresponds to the sequence TTCCTATGGGGGCTGTAGGGTGGATGGGACTGGGTGG $\mathrm{TA}^{6}$ - ATGAT ${ }^{10}$. Five PM2 alleles (Table 2 ) amplified by PCR were detected by a sequence based typing method of the PCR products and designated as Coja-DBB ${ }^{*} 01$ (alias $" * 01 "), " * 02 ", " * 03 ", " * 04 "$ and "*05". The three PM3 alleles designated as alleles "G-C", "G-G" and "A-C" were detected by a PCR-RFLP method using DraIII and HinfI (Table 1) to identify the SNPs "G/A" and "G/C" at the two SNP sites that are apart by $194 \mathrm{bp}$. Haplotype prediction was performed by PHASE and Arlequin programs [44,45]. Maximum-likelihood haplotype frequencies were predicted by a Bayesian statistical method of the PHASE program and an EM algorithm of the Arlequin program.

\section{RT-PCR, cloning CDNA and sequence determination}

Total RNA was isolated from the peripheral blood of six quails identified by the numbers302, 311, 312, 321, 322 and 323 and having the haplotypes (HTs) $1 / 1,2 / 3,1 / 3,1 /$ $4,4 / 5$, and $2 / 4$ respectively. The TRIzol reagent was used to isolate the total RNA as described by the manufacturer (Invitrogen, Groningen, Netherlands). Total RNA (0.2 ug) was synthesized to cDNA by using First Strand cDNA Synthesis Kit (Rever Tra Ace- $\alpha$-) and the oligo (dT) primer method (TOYOBO, Osaka, Japan). The CojaIIB specific primers were designed to amplify the exons $1-3$ (amplified size: from $411 \mathrm{bp}$ to $441 \mathrm{bp}$ ) and to detect polymorphisms on hyper variable $\beta 1$ domain (exon 2) by RT-PCR amplification with the sense primer (C2BNO2: 5'-GAGTGCCACTACCTGAACGGCACCGAGG-3') and the antisense primer (C2BNO5: 5'-GCGCCAGGAAGACGAGCCCCAGCAC-3'). These primer sequences were per- fectly matched with all CojaIIB genes on the Coja haplotype 1 to 5 in this study, providing confidence that the primers will amplify all the known CojaIIB genes with the same efficiency. cDNA (10 ng) was amplified by PCR with 2.5 units of GeneTaq NT polymerase (Nippon Gene, Toyama, Japan), using the thermal cycler GeneAmp PCR system 9700 . The reaction mixture $(10 \mathrm{ul})$ was subjected to 30 cycles of $30 \mathrm{sec}$ at $96^{\circ} \mathrm{C}, 30 \mathrm{sec}$ at $65^{\circ} \mathrm{C}$, and $30 \mathrm{sec}$ at $72^{\circ} \mathrm{C}$. The RT-PCR products were cloned into the pGEM-T Easy vector with the TA cloning kit according to the protocol provided by the manufacturer (Promega, Madison, WI, USA) and sequenced using the ABI3100 genetic analyzer (Applied Biosystems, Foster City, CA, USA) in accordance with the protocol of BigDye terminator method. To avoid PCR and sequencing artifacts generated by polymerase errors, 96 clones per individual were sequenced.

\section{Construction and screening of cosmid libraries}

Genomic DNAs for constructing the cosmid libraries were isolated from the red blood cells of two Coja haplotype heterozygote quails (311 and 322), having HTs 2/3 and 4/ 5 , by the Saponin- $\mathrm{NaCl}$ method [43]. The libraries were constructed by the SuperCos 1/Gigapack XL cloning kit according to the manufacturer's protocol (Stratagene, La Jolla, CA, USA). Approximately $5 \times 10^{5}$ independent colonies derived from these libraries were screened by using PCR products as hybridization probes obtained from the $527 \sim 586$ bp CojaIIB fragment generated by the sense primer $\mathrm{C} 2 \mathrm{BNO} 2$ and the anti-sense primer $\mathrm{C} 2 \mathrm{BNO} 5$ already described above in the RT-PCR section; the $276 \mathrm{bp}$ Tapasin fragment generated by sense primer Tapasin/e5-1 (5'-CCCAAAGAACCTGGTGGTGA-3') and anti-sense primer Tapasin/e5-4 (5'-AATGACCGTGGGTGACAA-3') and the 134 bp BRD2 fragment produced by the sense primer RING3/e4-1 (5'-GCAGCGGAGTGCAGAGACTT3') and anti-sense primer RING3/e4-3 (5'-CGAGTGCCAGCTGTCTCCTC-3'). 


\section{Genomic sequencing strategy}

The DNA of CojaIIB, Tapasin and BRD2 positive cosmids was sequenced by the shotgun method [46]. Individual sequences were minimally edited to remove vector sequences, and assembled into a contig using the Sequencher software (Gene Codes Co., Ann Arbor, MI, USA). Remaining gaps or ambiguous nucleotides were determined by the direct sequencing of the PCR products obtained with appropriate PCR primers or by nucleotide sequence determination of additional shotgun clones.

\section{Sequence analyses}

Nucleotide similarities among the sequences were calculated by using the GENETYX-MAC software ver 11.0 (Software Development Co. Ltd., Tokyo, Japan). Dot-matrix analysis was performed by using HARRPLOT Ver. 2.0 as part of the GENETYX package. Multiple sequence alignments were created using the ClustalW Sequence Alignment program at DDBJ [47]. The phylogenetic tree was constructed by neighbor-joining method of the Molecular Evolution Genetics Analysis (MEGA3.1) [48].

\section{Authors' contributions}

KHos, TS, HI and KHan participated in the design of this study. KHos and TS constructed the quail cosmid libraries. KHos, TS, SSuz, MT, SShi, SI, HH, YY, HI and KHan participated in sequencing and contig assembly of the cosmid clones and data analysis. KHos, TS, HI, JKK and KHan prepared this manuscript. All authors have read and approved the final manuscript.

\section{Additional material}

\section{Additional file 1}

Alignment of transcribed CojaIIBs for phylogenetic analysis. the nucleotide sequences of the $\beta 1$ extracellular domain regions (exon 2) (270 nucleotides in length) of MhcIIB genes for the 16 CojaIIBs the chicken haplotypic BLB sequences on B2 B4 B12 B14 B15 B19 and B21.

Click here for file

[http://www.biomedcentral.com/content/supplementary/1471-

2164-7-322-S1.pdf]

\section{Additional file 2}

Dot-matrix analysis among five Coja haplotypes $(A \sim J)$ between quail and chicken $(K)$ and between chicken B12 and B21 (L). Dot plot comparisons shows HT1 vs HT2 (A) HT1 vs HT3 (B) HT1 vs HT4 (C) HT1 vs HT5 (D) HT2 vs HT3 (E) HT2 vs HT4 (F) HT2 vs HT5 (G) HT3 vs HT4 (H) HT3 vs HT5(I) HT4 vs HT5 (J) HT2 vs chicken B12 (K) and chicken $\mathrm{B} 12$ vs $\mathrm{B} 21(\mathrm{~L})$. Numbers and blue circles in the images show the location of genome candidate remodeling (rearrangement) factors with the numbers 1 to 3 representing TB1 - TB3 respectively as outlined in Table 6. Gray background shows the gap within the segments that was determined by sequencing.

Click here for file

[http://www.biomedcentral.com/content/supplementary/14712164-7-322-S2.pdf]

\section{Acknowledgements}

The work was supported by grants from the Ministry of Education, Culture, Sports, Science and Technology of Japan, the Animal Genome Research Project of the Ministry of Agriculture, Forestry and Fisheries of Japan and the Advanced Research Project Type A, Tokyo University of Agriculture, No.02, 2006.

\section{References}

I. Klein J: Antigen-major histocompatibility complex-T cell receptors: inquiries into the immunological menage a trois. Immunol Res 1986, 5: 173-190.

2. Bourlet $Y$, Behar G, Guillemot F, Frechin N, Billault A, Chausse AM, Zoorob R, Auffray C: Isolation of chicken major histocompatibility complex class II (B-L) beta chain sequences: comparison with mammalian beta chains and expression in lymphoid organs. EMBO J 1988, 7:1031-1039.

3. Takahata N, Nei M: Allelic genealogy under overdominant and frequency-dependent selection and polymorphism of major histocompatibility complex loci. Genetics 1990, I 24:967-978.

4. Takahata N, Satta Y, Klein J: Polymorphism and balancing selection at major histocompatibility complex loci. Genetics 1992, 130:925-938.

5. Miller MM, Bacon LD, Hala K, Hunt HD, Ewald SJ, Kaufman J, Zoorob $R$, Briles WE: 2004 Nomenclature for the chicken major histocompatibility (B and Y) complex. Immunogenetics 2004, 56:26I-279.

6. Briles WE, Goto RM, Auffray C, Miller MM: A polymorphic system related to but genetically independent of the chicken major histocompatibility complex. Immunogenetics 1993, 37:408-4|4.

7. Miller MM, Goto R, Bernot A, Zoorob R, Auffray C, Bumstead N, Briles WE: Two Mhc class I and two Mhc class II genes map to the chicken Rfp-Y system outside the B complex. Proc Natl Acad Sci USA 1994, 9 1:4397-4401.

8. Fillon V, Zoorob R, Yerle M, Auffray C, Vignal A: Mapping of the genetically independent chicken major histocompatibility complexes B and RFP-Y to the same microchromosome by two-color fluorescent in situ hybridization. Cytogenet Cell Genet 1996, 75:7-9.

9. Miller MM, Goto RM, Taylor RL Jr, Zoorob R, Auffray C, Briles RW, Briles WE, Bloom SE: Assignment of Rfp-Y to the chicken major histocompatibility complex/NOR microchromosome and evidence for high-frequency recombination associated with the nucleolar organizer region. Proc Natl Acad Sci USA 1996, 93:3958-3962.

10. Kaufman J, Milne S, Gobel TW, Walker BA, Jacob JP, Auffray C, Zoorob R, Beck S: The chicken B locus is a minimal essential major histocompatibility complex. Nature 1999, 401:923-925.

II. International Chicken Genome Sequencing Consortium: Sequence and comparative analysis of the chicken genome provide unique perspectives on vertebrate evolution. Nature 2004, 432:695-716.

12. Ruby T, Bed'Hom B, Wittzell H, Morin V, Oudin A, Zoorob R: Characterisation of a cluster of TRIM-B30.2 genes in the chicken MHC B locus. Immunogenetics 2005, 57:116-128.

13. Shiina T, Hosomichi K, Hanzawa K: Comparative genomics of the poultry major histocompatibility complex. Anim Sci J 2004, 77:151-162.

14. Shiina T, Shimizu S, Hosomichi K, Kohara S, Watanabe S, Hanzawa K, Beck S, Kulski JK, Inoko H: Comparative Genomic Analysis of Two Avian (Quail and Chicken) MHC Regions. J Immunol 2004, I72:675I-6763.

15. Kulski JK, Shiina T, Anzai T, Kohara S, Inoko H: Comparative genomic analysis of the MHC: the evolution of class I duplication blocks, diversity and complexity from shark to man. Immunol Rev 2002, 190:95-122.

16. Collins WM, Briles WE, Zsigray RM, Dunlop WR, Corbett AC, Clark KK, Marks JL, McGraill TP: The B locus (MHC) in the chicken: Association with the fate of RSV-induced tumors. Immunogenetics 1977, 5:333-343.

17. Briles WE, Stone HA, Cole RK: Marek's disease: effects of B histocompatibility alloalleles in resistant and susceptible chicken lines. Science 1977, 195:193-195.

18. Longenecker BM, Gallatin WM: Genetic control of resistance to Marek's disease. IARC Sci Publ 1978:845-850. 
19. Simonsen M, Crone M, Koch C, Hala K: The MHC haplotypes of the chicken. Immunogenetics 1982, 16:5/3-532.

20. Hala K, Chausse AM, Bourlet $Y$, Lassila $O$, Hasler V, Auffray $C$ Attempt to detect recombination between B-F and B-L genes within the chicken $B$ complex by serological typing, in vitro MLR, and RFLP analyses. Immunogenetics 1988, 28:433-438.

21. Kaufman J, Volk H, Wallny HJ: A "minimal essential Mhc" and an "unrecognized Mhc": two extremes in selection for polymorphism. Immunol Rev 1995, 143:63-88.

22. Wilcox FH, Clark CE: Chicken-quail hybrids. J Hered 196I, 52:167-170.

23. Watanabe S, Nagayama F: Studies on the serum IgG level in Japanese quail. Japanese Poultry Science 1979, 16:59-64.

24. Inooka S, Takahashi S, Takahashi H, Mizuma Y: Immunologica traits in generations 7 to 12 of two lines of Japanese quail selected for high or low antibody response to Newcastle disease virus. Poult Sci 1984, 63: |298-1302.

25. Shimizu S, Shiina T, Hosomichi K, Takahashi S, Koyama T, Onodera $\mathrm{T}$, Kulski JK, Inoko H: MHC class IIB gene sequences and expression in quails (Coturnix japonica) selected for high and low antibody responses. Immunogenetics 2004, 56:280-29l.

26. Takahashi S, Inooka S, Mizuma Y: Selective breeding for high and low antibody responses to inactivated Newcastle disease virus in Japanese quails. Poult Sci 1984, 63:595-599.

27. Pradhan HK, Mohanty GC, Mukit A: Marek's disease in Japanese quails (Coturnix coturnix japonica): a study of natural cases. Avian Dis 1985, 29:575-582.

28. Shiina T, Shimizu C, Oka A, Teraoka Y, Imanishi T, Gojobori T, Hanzawa K, Watanabe S, Inoko H: Gene organization of the quail major histocompatibility complex (MhcCoja) class I gene region. Immunogenetics 1999, 49:384-394.

29. Shiina T, Oka A, Imanishi T, Hanzawa K, Gojobori T, Watanabe S, Inoko H: Multiple class I loci are expressed in the quail MHC. Immunogenetics 1999, 49:456-460.

30. Shiina T, Ota M, Shimizu S, Katsuyama Y, Hashimoto N, Takasu M, Anzai T, Kulski JK, Kikkawa E, Naruse T, Kimura N, Yanagiya K, Watanabe A, Hosomichi K, Kohara S, Iwamoto C, Umehara Y, Meyer A, Wanner V, Sano K, Macquin C, Ikeo K, Tokunaga K, Gojobori T, Inoko H, Bahram S: Rapid Evolution of MHC Class I Genes in Primates Generates New Disease Alleles in Man Via Hitchhiking Diversity. Genetics 2006, I73:1555-1570.

31. Corell A, Morales P, Varela P, Paz-Artal E, Martin-Villa JM, MartinezLaso J, Arnaiz-Villena A: Allelic diversity at the primate major histocompatibility complex DRB6 locus. Immunogenetics 1992 36:33-38.

32. Matsuo MY, Asakawa S, Shimizu N, Kimura H, Nonaka M: Nucleotide sequence of the MHC class I genomic region of a teleost the medaka (Oryzias latipes). Immunogenetics 2002, 53:930-940.

33. Shiina T, Dijkstra JM, Shimizu S, Watanabe A, Yanagiya K, Kiryu I, Fujiwara A, Nishida-Umehara C, Kaba Y, Hirono I, Yoshiura Y, Aoki T, Inoko H, Kulski JK, Ototake M: Interchromosomal duplication of major histocompatibility complex class I regions in rainbow trout (Oncorhynchus mykiss) a species with a presumably recent tetraploid ancestry. Immunogenetics 2005, 56:878-893.

34. Ohta Y, Goetz W, Hossain MZ, Nonaka M, Flajnik MF: Ancestral organization of the MHC revealed in the amphibian Xenopus. J Immunol 2006, I 76:3674-3685.

35. Kulski JK, Gaudieri S, Bellgard M, Balmer L, Giles K, Inoko H, Dawkins $\mathrm{RL}$ : The evolution of MHC diversity by segmental duplication and transposition of retroelements. I Mol Evol 1997, 45:599-609.

36. Shiina T, Tamiya G, Oka A, Takishima N, Yamagata T, Kikkawa $E$ Iwata K, Tomizawa M, Okuaki N, Kuwano Y, Watanabe K, Fukuzumi Y, Itakura S, Sugawara C, Ono A, Yamazaki M, Tashiro H, Ando A, lkemura T, Soeda E, Kimura M, Bahram S, Inoko H: Molecular dynamics of MHC genesis unraveled by sequence analysis of the 1796938-bp HLA class I region. Proc Natl Acad Sci USA 1999, 96: I3282-13287

37. Ghosh D: Object-oriented transcription factors database (ooTFD). Nucleic Acids Res 2000, 28:308-310.

38. Shiroishi T, Hanzawa N, Sagai T, Ishiura M, Gojobori T, Steinmetz M, Moriwaki K: Recombinational hotspot specific to female meiosis in the mouse major histocompatibility complex. Immunogenetics 1990, 3 I:79-88.
39. Crawford DC, Bhangale T, Li N, Hellenthal G, Rieder MJ, Nickerson $D A$, Stephens M: Evidence for substantial fine-scale variation in recombination rates across the human genome. Nat Genet 2004, 36:700-706.

40. Stewart CA, Horton R, Allcock RJ, Ashurst JL, Atrazhev AM, Coggill P, Dunham I, Forbes S, Halls K, Howson JM, Humphray SJ, Hunt S, Mungall AJ, Osoegawa K, Palmer S, Roberts AN, Rogers J, Sims S, Wang Y, Wilming LG, Elliott JF, de Jong PJ, Sawcer S, Todd JA, Trowsdale J, Beck S: Complete MHC haplotype sequencing for common disease gene mapping. Genome Res 2004, I 4: I I76-I I 87.

4I. Perez DR, Lim W, Seiler JP, Yi G, Peiris M, Shortridge KF, Webster RG: Role of quail in the interspecies transmission of $\mathrm{H} 9$ influenza A viruses: molecular changes on $\mathrm{HA}$ that correspond to adaptation from ducks to chickens. J Virol 2003, 77:3|48-3I 56.

42. Ratnamohan $\mathrm{N}$ : The management of Japanese quail and their use in virological research: a review. Vet Res Commun 1985, 9:1-14.

43. Shiina T, Ando A, Imanishi T, Kawata H, Hanzawa K, Gojobori T, Inoko $\mathrm{H}$, Watanabe $\mathrm{S}$ : Isolation and characterization of cDNA clones for Japanese quail (Coturnix japonica) major histocompatibility complex (MhcCoja) class I molecules. Immunogenetics 1995, 42:213-216.

44. Stephens M, Donnelly P: A comparison of bayesian methods for haplotype reconstruction from population genotype data. Am J Hum Genet 2003, 73: 11 62-1 169.

45. Excoffier L, Laval G, Schneider S: Arlequin (version 3.0): An integrated software package for population genetics data analysis. Evolutionary Bioinformatics Online 2005, I:47-50.

46. Shiina T, Tamiya G, Oka A, Yamagata T, Yamagata N, Kikkawa E, Goto K, Mizuki N, Watanabe K, Fukuzumi Y, Taguchi S, Sugawara C, Ono A, Chen L, Yamazaki M, Tashiro H, Ando A, Ikemura T, Kimura $\mathrm{M}$, Inoko $\mathrm{H}$ : Nucleotide sequencing analysis of the I46-kilobase segment around the IkBL and MICA genes at the centromeric end of the HLA class I region. Genomics 1998, 47:372-382.

47. DDB] [http://www.ddbj.nig.ac.jp/search/Welcome-e.html]

48. Kumar S, Tamura K, Nei M: MEGA3: Integrated software for Molecular Evolutionary Genetics Analysis and sequence alignment. Brief Bioinform 2004, 5:150-163.

Publish with Bio Med Central and every scientist can read your work free of charge

"BioMed Central will be the most significant development for disseminating the results of biomedical research in our lifetime. "

Sir Paul Nurse, Cancer Research UK

Your research papers will be:

- available free of charge to the entire biomedical community

- peer reviewed and published immediately upon acceptance

- cited in PubMed and archived on PubMed Central

- yours - you keep the copyright
BiolMedcentral 